\title{
Mechanisms of Rapid Adaptation to Environmental Stressors in Phytoplankton
}

Beatriz Baselga-Cervera ${ }^{1 *}$, Victoria Lopez-Rodas ${ }^{1}$, García Balboa ${ }^{1,2}$, Emma I Huertas Cabilla ${ }^{3}$ and Eduardo Costas ${ }^{1}$

${ }^{1}$ Genetics, Faculty of Veterinary Medicine, Universidad Complutense de Madrid, Avenida Puerta de Hierro s/n, 28040, Madrid, Spain

2Institute of Marine Sciences of Andalusia (CSIC), Polygon Rio San Pedro s/n 11519, Puerto Real, Cadiz, Spain

${ }^{3}$ Biotechnological Environmental Solutions (BES), Calle Ferráz 11, 28008, Madrid, Spain

\begin{abstract}
In the current scenario of global change, the impact of anthropogenic stressors is affecting the aquatic ecosystems, especially essential microorganisms such as phytoplankton, driving toward a biodiversity crisis. Classic ecotoxicology studies, focused on the immediate tolerance to pollution, have provide an over simplistic understanding of the long time impact of pollutants on phytoplankton (because of the usual misconception that evolutionary changes can only take place at long-term), inadequate to enable a suitable environmental risk assessment (ERA). Currently, concepts such as predictive ecology and integrating strategies are rising rapidly in prominence with regard to forecasting phytoplankton response to human impact. This review compiles the state of the art of multigenerational and evolutionary experimental studies and the mechanisms that trigger rapid adaptation in phytoplankton to anthropogenic stressors, highlighting the importance of ecology and evolution. Ecological realisms is one of the challenging parts of the stressors hazard, considering the broad phytoplankton diversity and the multifactorial character of the natural ambiances. Field and community experiments contribute to a better discerning of ecology interactions and network relations. Moreover, laboratory experiments exploring evolutionary mechanisms that allow rapid adaptation to contaminants (e.g., fluctuation analysis or ratchet procedures) have proven to be useful linking concentration of pollutants and adaptation strategy. When environmental change exceeds the range of variation that can be coped with by organisms through plasticity, selection processes may occur and evolutionary dynamics take place. Ecology and evolution are necessary to enhance the ERA knowledge and novel experiments may well emerge from the when contemplated as whole.
\end{abstract}

Keywords: Phytoplankton; Anthropogenic stressors; Rapid adaptation; Multi-generational studies; Ecology; Evolutionary toxicology; Environmental risk assessment

\section{Introduction}

During the last decades, increasingly evidences indicates that humans are performing an extraordinary unplanned experiment at planetary scale polluting numerous ecosystems inducing evolutionary changes and challenging the biotic diversity [1]. Consequently, several studies have considered humans the driving force of the "contemporary evolution" [2-4]. Anthropogenic activity is quickly changing the natural environment having a significant impact in ecosystems and biodiversity, leading the species in the race towards adaptation. Sometimes changes are so fast that certain species simply cannot adapt [5-7]. Declining biological diversity worldwide, at both genetic variability within and at species levels, is one of the main threats that species are facing nowadays, the estimated rate of annual loss is around $1 \%$ in species populations and habitats [8]. The diversity crisis is a problem of the utmost importance, and hence basic research is urgently needed to provide $[9,10]$ useful information that allows the design of future strategies and apply conservation policies able to mitigate the biodiversity crisis and reduce environmental degradation $[11,12]$.

On global basins, aquatic biome represents around the $71 \%$ of the total earth surface [13]. The aquatic ecosystems underpin a wide variety of species being one of the principal biomes affected by the emerging biotic crisis. During the past century, a large variety of chemical pollutants has been extensively released to the aquatic environment of both natural-occurring pollutants (e.g., hydrocarbons) [14,15], heavy metals [16], steroids [17,18], antibiotics [19,20], climate change [21] and synthetic compounds (e.g., herbicides or pesticides) [9]. These environmental stressors lead to physiological changes, population size reduction, and shifting the main traits of the aquatic populations imposing directional selection and threatening the species richness.
Since phytoplankton are the main primary producers in aquatic ecosystems supporting approximately half of the Earth's photosynthesis [22], play a key role in biogeochemical and ecological cycles, in the regulation of atmospheric $\mathrm{CO}$ and maintenance of upper trophic levels sustaining the aquatic food web, addressing the reasons behind phytoplankton decay should be better examined $[23,24]$. The Phytoplankton comprise drifting life forms of photosynthesizing microscopic organisms that inhabit the euphotic zone of oceans, seas, and freshwater basin ecosystems worldwide, whose spatial distribution is primarily determined by the motion of the water column. Phytoplankton is extremely diverse including 11 phyla of prokaryotic and eukaryotic microorganisms with haploids and diploids species, some asexual and other having recombination [25]. Moreover, the different species of phytoplankton have very diverse environmental demands in nutrients, light intensity, temperature, sinking and others, which determines their adaptive and ecological reactions, and variations in the rates of individual processes and shifts in species succession [26,27]. Consequently, investigate the differential capacity of the response of phytoplankton to environmental stress is a key issue in understanding the future repercussions of global change on the functioning of aquatic ecosystems.

*Corresponding author: Beatriz Baselga-Cervera, Av. Puerta de Hierro s/n, Universidad Complutense de Madrid, Madrid, Spain, Tel: +34913943769; E-mail: bbaselga@ucm.es

Received September 12, 2016; Accepted September 21, 2016; Published September 27, 2016

Citation: Baselga-Cervera B, Lopez-Rodas V, García-Balboa C, Cabilla ElH, Costas E (2016) Mechanisms of Rapid Adaptation to Environmental Stressors in Phytoplankton. J Environ Anal Toxicol 6: 405. doi: 10.4172/2161-0525.1000405

Copyright: (C) 2016 Baselga-Cervera B, et al. This is an open-access article distributed under the terms of the Creative Commons Attribution License, which permits unrestricted use, distribution, and reproduction in any medium, provided the original author and source are credited. 
Citation: Baselga-Cervera B, Lopez-Rodas V, García-Balboa C, Cabilla EIH, Costas E (2016) Mechanisms of Rapid Adaptation to Environmental Stressors in Phytoplankton. J Environ Anal Toxicol 6: 405. doi: 10.4172/2161-0525.1000405

Page 2 of 14

Forecasting the effects of the human stressors under a global change scenario upon the biological diversity and ecosystems is the aim of the predictive ecology [28]. Within the predictive ecology, ecotoxicology is the field of knowledge that study the relationships between stressors substances or pressures and exposed species/ecosystems [29]. The principal challenges that ecotoxicology are currently facing is predicting the ecological risk of the widespread anthropogenic stressors and the increasing number of substances release to the environment [30] and the additional toxicological complexity of multiple pollutants or mixtures, in a multifactorial biosphere. In the aquatic environment anthropogenic chemicals indeed seems to be widespread and the mixture of stressors appear to be the norm [31-33]. Moreover, the different exposure patterns influence the possible ecological outcomes in the aquatic populations $[34,35]$.

In order to face these issues, several standardized toxicity tests and regulatory toxicity protocols have been recommended to evaluate growth rate inhibition in microalgae and other microorganism [3639]. Considering that phytoplankton represents keystone species of the aquatic environment, multiple laboratory studies have estimated the tolerance to pollution of phytoplankton species following the standardized tests [40] or by evaluating the acute effect of a toxicant [4144]. Despite the importance of these protocols, it is naïve to expect that simple test can assess the complexity of the domain of pollutants effect in ecosystems [45]. A better inclusion of ecology in the environmental risk assessment (ERA) has been recently acknowledged [46,47]. This paradigm provide an overly simplistic scheme for creating a predictive model of environmental risk, unable to screen the complexity of threaten biological networks. For instance, the integration of the information for the environmental risk assessment (ERA) approaches is gaining recognition (p. e. the joint project of the WHO-IPCS/US-EPA (WHO, 2001)). Within this scheme, some risk assessment concepts have risen importance such as integrated testing strategies (ITS) $[48,49]$ or adverse outcomes pathways (AOPs) [50-52]. The ITS concept combine information for the risk assessment of non-test and test data, both standard and non-guideline tests, integrating to the regulatory tests information the outcomes from scientific experiments or observations. AOPs contemplates that although every toxicity mechanistic detail for a given pollutant might be unclear, linking the molecular initiating event and the adverse outcome that occur at a biological level can provide a guide tool towards key event relationship reaching the same endpoint, for instance, molecular genetics or evolutionary relationships.

Currently, under the integrated approach it can be stress the need of more ecology relevance in the ERA [47,53]. ERA can benefit from the increased knowledge on biological systems and evolution, which have been given low priority [11], and put aside outdate extrapolations between species and to natural environments of toxic direct adverse outcomes at in vivo test [54]. Moreover, when referred to phytoplankton, which taxonomy diversity spans across several phyla, extrapolating the effect of a pollutant between divergent species may be therefore misleading. Therefore, in the ecotoxicology field are rising experimental adaptation approaches to examine long-term consequences of human stressors, exploring the multigenerational exposure regimes, transgenerational effect and the evolutionary pathways in human-altered environments.

The ability of organisms to adapt and evolve had been scarcely taken into account in ecotoxicology and ERA, because of the usual misconception that evolutionary changes can only take place at long term. However, the evolution capacity can be particularly rapid in microorganisms, as widely documented by laboratory experiments [55-58]. Darwin's seminal idea of evolution by natural selection of best-adapted organisms in populations herewith other factors as chance and historical contingency are used to explain all kinds of evolutionary change. Several evolutionary forces including mutation, genetic drift, selection and migration determined the evolutionary destiny of natural populations. In the prevailing view, natural selection for and against new mutations is the main driving force of evolution. Because selection usually reduces genetic diversity within populations, there is a controversy in molecular evolution known as the neutralims-selectionism debate $[59,60]$ and non-Darwinian models have been recently proposed $[61,62]$. Often these controversies have a strong theoretical component. An experimental approach testing the Darwinian view could help in the debate. Moreover, adaptation experiments comparing different species can be useful in the AOPs and environmental conditions more realistic can implement the ERA. These mechanisms could be of great importance when assessing phytoplankton responses under future scenarios of global change.

This review focuses on phytoplankton resilience to ambiance stressors in experimental research, attempting to compile the state of the art of these studies. We focus on the adaptation studies assessing rapid adaptation in phytoplankton trigger by toxic stressors, studying the adaptation limits, the evolutionary mechanisms involved, the population characteristics that influence adaptation (e.g., population size, initial genetic variability, community interactions) and the importance of protocols that resemble natural conditions.

\section{Experimental Studies of Phytoplankton Adaptation to Environmental Stressors}

The Phytoplankton population are subjected to a continuous change due to the constant release of human stressors to the aquatic environment $[63,64]$. Under these changing ambiances only by means of adaptation processes the phytoplankton populations can persist. Sensing this, addressing the resilience ability and mechanisms of the phytoplankton populations is necessary for the ERA of anthropogenic pollutants.

The study of the adaptive processes require the exposure and evaluation several successive generations to new conditions. The toxicology approach that aboard the long-term impact along several generations of an exposure regime is the multigenerational toxicity. These studies comprise more than two life-cycles test, in which more than one generation have been directly exposed to the pollutant. In most of the current ecotoxicity studies in phytoplankton, owing to the short generation times, the approach is multigenerational [6568]. There is however, a specific part of the multigenerational toxicity studies, the transgenerational toxicity, analyzed the effects of a toxic substance upon subsequent generations through parental population expositions, which induce a change in the germ line and propagate. In our case, most of the microalgae are unicellular organisms, the toxicant have to induce changes in the parental cells that might be transferred changes induced in single or subsequent expositions to the subsequent generation. Parental changes have to be related with the changes in the genome or epigenetics changes (modifications in the inheritance patterns, affecting gene expression without involving changes in the genome sequence $[69,70]$. Epigenetic features haven been described in microalgae such as Chlamydomonas sp. or Chlorella sp. [71,72]. Derived from this perspective is the trans-generational toxicology study of Pomati and Nizzetto [73] in microalgae that focuses on the links between adaptation and ecological dynamics.

Experimental multigenerational adaptation studies in phytoplankton can measure the direct result of a selective procedure 
Citation: Baselga-Cervera B, Lopez-Rodas V, García-Balboa C, Cabilla EIH, Costas E (2016) Mechanisms of Rapid Adaptation to Environmental Stressors in Phytoplankton. J Environ Anal Toxicol 6: 405. doi: 10.4172/2161-0525.1000405

Page 3 of 14

upon a pollution or community (effect assessment) or additionally assess the evolutionary process involved (evolutionary assessment). The effect of pollutants on the genetics of natural populations is the field of the evolutionary toxicology [74-77]. Evolutionary toxicology makes use of the conceptual basis of evolution, toxicological concepts and conservation biology reviewed by Bickham [78] and the ecological settings and dynamics are shaped by the evolutionary process $[73,78,79]$. Both disciplines, ecology and evolution, are tightly intertwined however, there is a lack of experimentation in phytoplankton. The evolutionary genetics and ecology have an extraordinary conceptual richness that could be very useful to ERA, by means of evolutionary assessment functional or genetic redundancy can be found reaching the same endpoints [80-82]. One relevant evolutionary approach is the occurrence of randomly emerging populations in small time scales, such as those that rise under rapid environmental changes from multigenerational expose populations, by means of phenotypic plasticity and evolutionary responses [83-85].

However, evolutionary assess experiments are normally performed with laboratory strains and clonal phytoplankton populations. If the ERA trend of integrating the complexity of the ecosystems, lethally observed in one specific strain or population should not be extrapolated to the species levels, the tolerance level might change [86], ecosystems do not remain stable and the responses do not propagate linearly [73]. A better integration of the ERA of the jeopardized phytoplankton environments can be provided screening the diversity of the populations, addressing natural communities and performing in situ experiments.

Diversity is directly related with the community response to environmental disturbance and is regarded as leading to better stability at the level of communities and ecosystems [87-90]. Diversity of phytoplankton can be contemplate within species level, the genetic variability [91], and among species, variability present in the community or ecosystem [92]. The intra-species diversity influence in the resilience of phytoplankton is contemplated in the evolutionary studies by testing non-clonal populations or several strains. Nevertheless, a few papers have exposed natural planktonic communities to toxicants during several generations addressing the alterations at one-species populations and community levels. Prominent examples are the paper of Low-Decarie et al. [66] and Tatters et al. [35] which found district outcomes comparing the response of single species and communities. Furthermore, differences can rise from comparing laboratory strains with natural communities. In situ assessment of the impact on the phytoplankton community in their natural ambiance best achieve the integration approach of the ERA (assessing e.g., site characteristics, community parameters, environmental hallmarks, toxicological information [93], in both experimental studies [73] or analyzing contaminated sites $[34,94]$, despite repeatability problems.

Here, we examine the phytoplankton multigenerational experimental adaptive studies. First, the adaptation effect assessing studies, which seek for a more complex models and conditions setting aside the genetic and evolutionary approaches. Secondly, we cluster the multigenerational evolutionary adaptation studies under human induced selective conditions.

\section{Transgenerational and multi-generational non-genetical adaptive studies}

In the recent times, Phytoplankton studies attempt to face some challenges in the risk evaluation of the anthropogenic pollutants as the multi-generational impact or ecological realisms, without direct assessing of the evolutionary trails. The number and duration of the pollutants exposure can determine the adaptation response of a population. For example, the transgenerational effects of a single exposition to the toxicant can induce changes that persist over two subsequent generations, as shown in a natural phytoplanktonic community experimentally exposed to trichlosan [73]. Moreover, some studieshave confirmed the same performance under elevated $\mathrm{pCO}_{2}$ comparing the same species during a short and long term experiment as compared by Müller [95] in two species of Emiliania. Alternatively, Stachowski-Haberkorn et al. [96] investigated the ability of polyclonal Tetraselmis suecica to adapt under a very long exposition period to the herbicide diuron $(5 \mu \mathrm{g} / \mathrm{L})$ and the possibility of a specific resistance to be fixed by the population and maintained during long non-exposition periods.

Different outcomes can be found in long-term community studies comparing the original and artificial communities, significant shifts in the species distribution were found in a marine dinoflagellate bloom and artificial communities recombined from the bloom isolates under different $\mathrm{CO}_{2}$ scenarios [35]. Furthermore, the work made by LowDecarie et al. [66] study several freshwater species response to a gradual increase and afterwards maintenance of a $\mathrm{CO}_{2}$ pressure individually, pairwise communities and six species community. In these cases, the $\mathrm{CO}_{2}$ altered the dynamics of the population's growth, increasing the rates, and pairwise populations significantly predict the competition outcome of the six species community showing a potential as a mean to predict response in natural ambiances.

Non-genetic adaptation trials in phytoplankton address different experimental approaches to assess the anthropogenic perturbation. Under the novel environmental properties, these studies try to reproduce different possible expositions, such as different patterns environmental pressure, and more accurately natural conditions, using natural communities, species mixtures and non-clonal populations. These kind of experiences enable a more realistic picture of the adaptation capacity under selective conditions and continue to gain prominence being very relevant to ERA. However, study the adaptation trajectories and evolutionary responses in the majority of the cases is mostly indirectly by means of equations and by means of theoretical models. Further understanding could be achieved with some genetic studies such as mutation rates or initial genetic variability; for instance, Low-Decarie et al. [66], Tatters [35] and Müller et al. [95] do not perform any genetic evolutionary approach rather than strain or community structure response, Stachowski-Haberkorn et al. [96] propose two possible adaptation strategies but neither of them can be demonstrated with the experiment nor with the DNA study and Pomati and Nizzeto [73] calculated the evolutionary responses by means of the Price equation, but they point to other approaches to study the evolutionary aspect and study the evolutionary forces involved might be interesting.

\section{Evolutionary adaptation studies}

In order to evaluate the evolutionary potential of phytoplankton under contaminated environments, it is necessary to assess the adaptive mechanism that takes place in each situation. Persistence under extreme conditions require different features in which lay a successful adaptation, ad hoc and heavily dependent on the rate of change and the organism. Each adaptive feature influence livelihood, first persistence hinges on phenotypic or behavior plastic modifications, which are the genotypes capabilities to produce changeful phenotypes and conducts in response to ambient conditions $[97,98]$. Once the physiological and behavior limits of a species to a stressor (plasticity) is exceeded, only adaptive evolution can ensure survival. Adaptive evolution is the change 
Citation: Baselga-Cervera B, Lopez-Rodas V, García-Balboa C, Cabilla EIH, Costas E (2016) Mechanisms of Rapid Adaptation to Environmental Stressors in Phytoplankton. J Environ Anal Toxicol 6: 405. doi: 10.4172/2161-0525.1000405

in the genetic frequencies that involve a change in the phenotypic frequencies propitiated by selection on hereditary variation and as state by Sniegowski and Lenski [99] and Sniegowski [100], depends solely on the occurrence of new mutations that confer resistance.

On the evolutionary studies in phytoplankton features are typically evaluate at the level of whole cells, measuring fitness and phenotypic traits of interest such as, cells sizes or photosynthesis [101-103]. Fitness is the principal trait study in phytoplankton experimental evolution and the fitness of a genotype is study as the competitive ability to growth under a selection ambiance, valuating the implication of a genotype in the population persistence. In addition, most of the evolutionary experiments in phytoplankton are made with clonal population eliminating the diversity within species and enable to study the heritable change attributed to novel mutations except that epigenetic effects cannot be discarded $[91,102,104]$. However, for the ERA interspecific variation in both plastic and genetic evolutionary responses determinates the evolutionary potential of a population and reliability when extrapolating the result to natural populations. Sensing this, several phytoplankton studies underline the importance of the high variability presented in the phytoplankton populations $[84,104,105]$ and some of the evolutionary experiments are performed in several clones seeking a more realistic prediction [106,107]. Another determinant characteristic in the evolutionary outcome is the population size influencing the evolutionary rate and the maximal rate of environmental change [108]. Furthermore, the exposure history of the genotype con influence the response against an stressor $[4,109,110]$.

Evolutionary toxicology seeks to clarify the type of evolutionary forces that take place, the genetic mechanism, the rapidity in time and over generations, adaption to increasing selective pressures above the initial lethal doses, the mutation rate of a species to a stressor and the presence of rare spontaneous mutations in the initial population (prior to exposition). By means of experimental evolution, different approach have been essay to characterize several of the evolutionary adaptation response of phytoplankton under selective pressures. Each kind of experiment gives information of genetic and/or plastic changes providing evidences to insight the evolution performance in a concrete situation.

\section{Evolutionary characterization of plastic and genetic evolutionary responses}

To date, a wide number of phytoplankton evolutionary studies essay measure the component of evolutionary response through phenotypic discriminating changes without underlying genotypic changes (phenotypic plasticity), from those involving changes in the genotype. Discriminating both components is possible in laboratory experiments because phytoplankton enable to subdue several replicates of the same population to an environmental pressure, evolve them during multiple generations. The evolved population features can be compared with one or more control population evolving in parallel under control conditions or with their own ancestor traits. These experiments measure control/ancestor versus exposed replicates evolutionary responses to environmental changes and the implicated adaptive forces. Moreover, when such experiments are carried on with several strains or different clones from the same species, the phenotypic plasticity of a specie or a population can be investigated.

Experimental evolution comparing exposed populations to evolved controls in phytoplankton under changing environment have mainly studied the ocean acidification though increasing the atmospheric pressure of $\mathrm{CO}_{2}$. Several reviews assessing this matter have been performed, such as Collins et al. [104], Reusch and Boyd [111] and Litchman et al. [112]. The experimental divergence is broad; comparing abrupt with gradual selection, long-term and short-term experiments, community and single species experiments, one or several environmental changes and so one. Because of factorial combination of possible regimes of environmental changes and population conditions, different experiments can addressed. However, all the latter reviews compile phytoplankton treatments under selective conditions in which direct (plasticity) and long-term (evolutionary) changes in the growth rates can be disentangled comparing the results with populations maintain under near-ambient conditions (controls).

In the other hand, experiments using ancestral versus derived populations compare the evolved traits values with the initial traits values estimated prior to exposition to the selective agent. Unlike the experimental evolution compare with evolved clones, these procedures valuate the total change experience by the population because you know input trait values instead of comparing with evolved controls. Based in the theoretical experiment of "replaying life's tape" of Gould [113] in which Gould wanted to emphasize the contingency of evolution, these approaches allow a reference to the ancestral population an hypothetical step back to the past. To our knowledge, only four studies have been made in phytoplankton to compare ancestral versus derived populations, and they can be grouped into two groups. The first group was an indirect review performed by Collins et al. [104], in which from the data obtained by Low-Decarie et al. [66], they compare the ancestral growth rate of six different species of freshwater phytoplankton with its derived $\mathrm{CO}_{2}$ exposed cultures. From this work, it can be inferred that the principal adaptation response is plasticity in all the species and the evolutionary response is disposable. As discuss by the author, probably the experiments were not enough large or consistent to foster evolution. The other group cluster the ancestral vs derived experiments in phytoplankton derived from the work of Travisano et al. [56] in bacteria and try to disentangle some of the evolutionary forces acting within the population. The experimental procedure consists of using identical replicates from a single ancestral genotype in which several specific features are measured at the beginning and after a high number of generations have taken place. The effect of the adaptation and chance (stochastic changes altering allelic frequencies) can be explained by the differences between the mean values of the initial and final measurements. The historical contingency (the effect of certain genetic changes in the past that promote or constrain evolutionary performance [114] can be evaluated by performing the same experiment using several independent ancestral genotypes [56]. A second experiment returning to the initial conditions during several generation, would explain if adaptation is supported by plasticity or by genetic adaptation. The different forces implicated in the evolutionary forces in each study, number of generations, the type of adaptation and the differences between the ancestral versus deriver evolutionary studies are summarized in Table 1.

A wide range studies based on explaining the principal pathways driving adaptation and evolution can be performed. Disentangling the plasticity and the evolution effect enable a greater understanding of possible future outcomes under the environmental change induced by the pollutants release to the ambiance, evaluating direct effect and long-term changes in the populations. The range of possible scenarios is enormous, a possible balance outcome to essay ER is to apply several experimental approaches or combine several factors in a single treatment or a systematic combination regime [115]. Taking into account that evolution is a continuous stochastic process, studying both ancestral and evolved controls with respect to the treatments is 
Citation: Baselga-Cervera B, Lopez-Rodas V, García-Balboa C, Cabilla EIH, Costas E (2016) Mechanisms of Rapid Adaptation to Environmental Stressors in Phytoplankton. J Environ Anal Toxicol 6: 405. doi: 10.4172/2161-0525.1000405

Page 5 of 14

\begin{tabular}{|c|c|c|c|c|c|c|c|}
\hline Organism & $\begin{array}{l}\text { Environmental } \\
\text { change }\end{array}$ & $\begin{array}{c}\text { Generations } \\
\text { (selection+control } \\
\text { conditions) }\end{array}$ & $\begin{array}{c}\text { Plastic } \\
\text { response } \\
\text { (grow rate) }\end{array}$ & $\begin{array}{l}\text { Total } \\
\text { evolutionary } \\
\text { response } \\
\text { (growth rate) }\end{array}$ & $\begin{array}{c}\text { Evolutionary forces } \\
\text { implicated (growth rate) }\end{array}$ & Other traits measured & References \\
\hline $\begin{array}{l}\text { Prorocentrum } \\
\text { triestinum } \\
\text { (two strains) }\end{array}$ & $\begin{array}{l}\text { Double nutrients } \\
\text { and } 25^{\circ} \mathrm{C} \text {. }\end{array}$ & $400+120$ & $18 \%$ & $72 \%$ & $>95 \%$ Adaptation & $\begin{array}{c}\text { Cells size } \\
\text { (Chance, history and } \\
\text { adaptation) }\end{array}$ & [136] \\
\hline $\begin{array}{l}\text { Alexandrium } \\
\text { minutum } \\
\text { (two strains) }\end{array}$ & $\mathrm{pH} 7.5$ and $25^{\circ} \mathrm{C}$ & $180-250+6-8$ & $32 \%$ & $68 \%$ & $\begin{array}{c}20 \% \text { Adaptation } \\
75 \% \text { History } \\
5 \% \text { Chance }\end{array}$ & $\begin{array}{l}\text { Toxic cell quota } \\
\text { (Plastic response influence } \\
\text { mainly by history and less by } \\
\text { chance) }\end{array}$ & [110] \\
\hline $\begin{array}{c}\text { Microcystis } \\
\text { aeruginosa } \\
\text { (three strains) }\end{array}$ & $\begin{array}{c}\text { Double nitrate } \\
\text { concentration } \\
(0.07 \mathrm{M}) \text { and } 30^{\circ} \mathrm{C}\end{array}$ & $87+7$ & $34 \%$ & $66 \%$ & $\begin{array}{c}66 \% \text { Adaptation } \\
\text { 33\% Chance }\end{array}$ & $\begin{array}{l}\text { Toxin production } \\
\text { (Chance) }\end{array}$ & [124] \\
\hline
\end{tabular}

Table 1: Summary table of the ancestral vs derived phytoplankton studies. Responses are measure in each study at the population level.

an interesting approach that solely need measurements of the initial traits and control under near-ambient conditions. In addition, the demographic constrains, initial genetic variability and the history of the phytoplankton can change toward a determinate direction and the strength of the selection. One interesting idea raised by Collins et al. [104], is investigating the plastic responses at a metabolic level instead of the whole cells. Searching for common metabolic pathways to predict the plastic response to selection is interesting given the great differences that present phytoplankton even at functional groups. Understanding subcellular process can help to identify changes in several species induced by a stressor and make more accurate predictions of important phenomenon as carbon fixation by microalgae or oxygen production.

\section{Maximum adaptation capacity experiments}

The rate of change of many ecosystems have exceed the initial predictions, therefore assessing the maximum adaptation capacity facing a stressor might be interesting for understanding the possible future biodiversity scenarios. Several adaptation approach have been performed in microalgae studying adaptation capacity under gradual increase of the selective agents $[65,116,117]$. One of the crucial steps for adaptation is the population size $[108,118]$.

An interesting system to study long-term stressor exposition to evaluate the evolutionary response was designed by Reboud [119]. The ratchet protocol consist several cycles of increasing the selection intensity of three sets of treatments, and an unexposed set, of large populations of microalgae. In the current experiment, the population is re-cloned from a single cell thus genetic variations can be attributed to random arising mutations as review by Lenski and Sniegowski [99]. Each cycle consist in multiple-days trial, estimated from each particular strain growth rate, were control and treatment sets founded with large populations from the same parental strain and incubated under the same conditions. At the end of each cycle, the growth of each treatment set is valuated in contrast with the control set and decisions are made; if the growth reach or exceeds the cell density threshold, the treatment set is transferred to the next cycle with a higher dose of the selective agent, if not the dose prevail. When after several cycles growth do not reach the threshold, the microalgae has been given the highest dose of a pollutant (stressor agent) that it can cope with (the adaptive boundary) (schematic representation of the ratchet protocol is given in Figure 1).

In the few cases where this procedure have been applied, resistance diversity has been found between species and regarding the selective agent (see Table 2 and references therein). The number of ratchet cycles depends on the species and the capacity of the adaptive cells to resist the increasingly selective conditions.
As previously noted by Huertas et al. [106], habitat preference and the taxonomic group are involved in the selection process, microalgae of the chlorophyte division reach higher levels of selective pressure than the cyanobacteria and the other taxonomic groups. Marine algae presented in general lower rates of adaptation than freshwater species. Orellana et al. [120], later patented the development of a biosensor, using the ratchet protocol as the chosen procedure to select the resistant bio-receptor of the device.

The novelty of Reboud ratchet system is based in the combination of high-density populations under strong selection pressures, notwithstanding the systematic ratcheting-up of selective pressure, a substantial growth was ensured at each step of the system and hence new arising mutations can take place and propagate. Moreover, on carrying out the ratchet protocol different evolutionary dynamic can take place, differences in replicates can indicate that resistance can be attained separately by random rise of adaptive genotypes. Data obtained when applying the ratchet protocol indicate that the maximum adaptation capacity can be achieved between 140-420 days (90-310 generations) depending on the stressor and species. This time scale suggests that phytoplankton can evolve, in order to survive, at an astonishing speed.

This procedure enables an insight into the maximum adaptation ability of a strain, giving an idea of the composition of the possible future communities under scenarios of increasing pollutants. One interesting consideration is if the results obtained based on a single starting clone can be drawn at species level, taking into account initial variability the results might be likely to exceed those obtained with clonal populations. But in a population with an initial variability we need to distinguish between the plasticity and the genetic adaptation, and by means of the ratchet protocol we only consider the genetic adaptation. In our knowledge, no study of this kind has been performed under natural conditions and might be interesting, as in any other procedures, to compare the outcome obtained under real conditions.

\section{Experiments discriminating pre-selective and post-selective genetic adaptation}

Fluctuation test is a long-term genetic experiment first described by Luria-Delbrück [55] in bacterial cultures and later adapted by Lopez-Rodas et al. [121] for liquid cultures and microalgae. The microorganism is subjected to the extensor a period of time long enough to ensure evolution of the population, indicating full speed evolution in opposition to longer time-scales that other organisms need to evolve. The intention of this experiment was to distinguish the origin of the adaptation to a selective pressure exposition, discriminating between a pre-selective adaptation by random spontaneous mutations (prior the selective agent exposition) and post-selective adaptation by tolerance 
Citation: Baselga-Cervera B, Lopez-Rodas V, García-Balboa C, Cabilla EIH, Costas E (2016) Mechanisms of Rapid Adaptation to Environmental Stressors in Phytoplankton. J Environ Anal Toxicol 6: 405. doi: 10.4172/2161-0525.1000405

Page 6 of 14

to the stressor or genetic adaptation due to direct exposition (as a response to selection). Two sets of experiments, one acting as controls and the other as treatments, were necessary (Figure 2). Both sets must be genetically identical from the same parental culture isolated from a single cell (clonal propagation). In Set 1 (treatment trials) are inoculated with a low cell density of approximately (reasonably low so as to assume the absence of pre-existing mutants) and growth to reach a high concentration. At this stage, each tube of Set 1 was exposed to the selective agent whereas Set 2 (control trials) was launched with a same cells concentration as Set 1 and using identical selective conditions. After a selected period of time, which is long enough for the rising mutant population to produce detectable progeny, all replicates of both sets were counted.

In Set 2 samples variance would be equal to the mean (consistent with the Poisson model), and there would be a low variation from tube to tube, probably due to random sampling errors. However, sample variance/mean ratio in Set 1 can result in three possible independent results:

a) post-selective adaptation: low variance, consistent with the Poisson model and similar variance/ mean ratios between Set 1 and Set 2. Resistant cells arose during the exposition to the selective agent, every cell has an equal probability to develop resistance.

b) pre-selective adaptation: high variance, is not consistent with the Poisson model (i.e., variance $>$ mean) and a variance/mean ratio of Set 1 is significantly greater than a Set 2 ratio (fluctuation). Resistant cells adapted by a rare spontaneous mutation presented in the population before the exposition.

c) no adaptation: if no resistant cells grow after the period of incubation in any replicates (neither Set 1 or Set 2).

Likewise, fluctuation analysis enables the estimation of the mutation rate $(\mu)$, the rate of appearance of resistant cells to the selective agent. Additionally, the mutation-selection balance (q), the equilibrium between the rise of mutant deleterious alleles and their elimination by chance or natural selection, can be estimated.

A summary of the studies that have applied the fluctuation analysis to assess the impact of anthropogenic stressors on phytoplankton is given in Table 1. Consistent with expectations, the present body of work indicates that not all the species could adapt to extremely stressful doses as only 35 species were not able to adapt out of the 105 fluctuation analysis performed. Adaptive genotypes presented two possibilities: a post-selective adaptation by tolerance to stressors (during the exposition) or by a pre-selective adaptation by rare spontaneous mutation (prior to the exposition). Post-selective adaptation was observed in 11 cases, coinciding with those where the lowest concentrations or less harmful conditions were assayed. It could be then concluded that $83 \%$ of the species were capable of adapting by rare pre-existing spontaneous mutations when matched with usually lethal doses of exposition (p.e. the TNT or lindane expositions). In contrast, acclimation occurred under exposition only to sub-lethal doses.

Moreover, referring to Table 3, differences between species can be seen. Phylum differences can be found regardless of the pollutant; Cyanobacteria (Microcystis sp., Pseudoanabaena sp. and Prochloron sp) seem to be more sensitive to extremophile ambiances, hidrocarbons and osmium than the species belonging to the phylum Chlorophyta (Scenedesmus sp., Dictyosphaerium sp. and Dunaliella sp.). As for heat stress, differences in tolerance were related to the original habitat,

\section{RATCHET PROTOCOL}

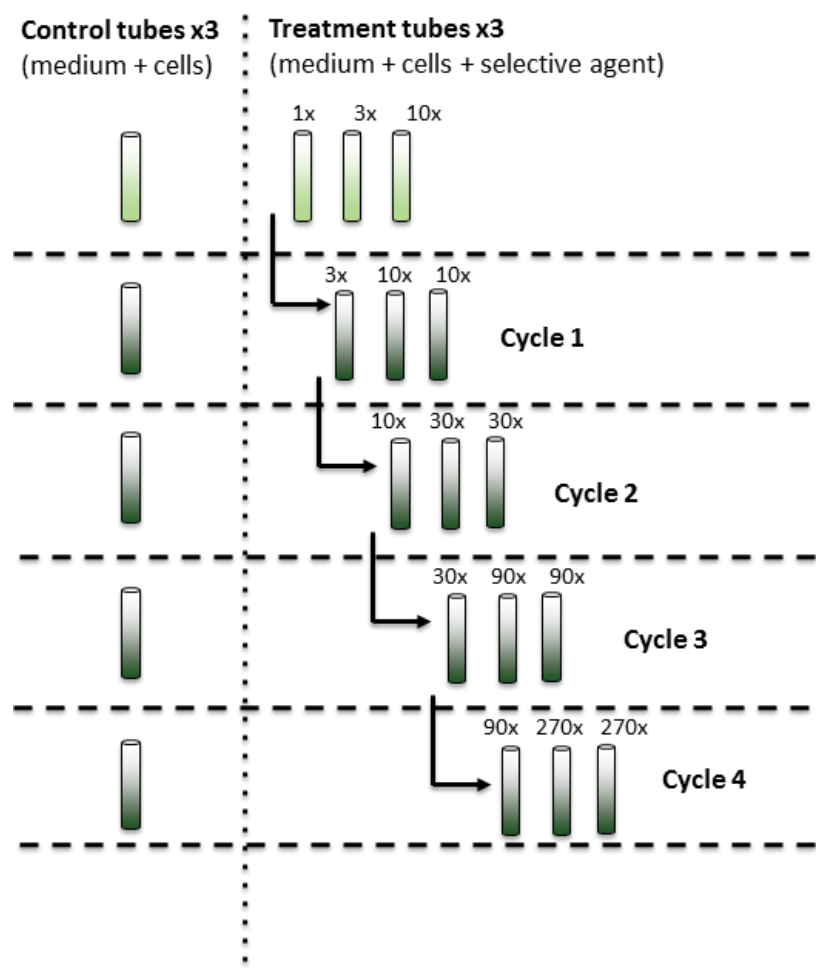

Figure 1: Schematic diagram of the Ratchet protocol experiment [115]. Four groups of three replicates, one control group and three groups each with the three initial doses of the toxic agent are represented in each ratchet cycle. Every 20 days (consider a new ratchet cycle )all the replicates are counted and the tubes reaching the same growth as the control replicates are transfer to the next concentration, those that do not reach the concentration are maintain at the same concentration. The experiment can be perform until a dose where no detectable growth take place.

such as oceanic and marine algae were found to be more sensitive to rising temperature, followed by microalgae isolated from coastal waters and continental waters. Furthermore, Table 1 also highlights that Scenedesmus sp. is the species which exhibits the highest adaptation capacity in general to all the stressors.

Another experiment named Newcombe analysis [122], also study the type of adaptation flowing a similar design. The principal differences can be seen in the experimental procedure, Newcombe analysis is less quantitative than the Fluctuation analysis but more graphical. The experimental design consists of the preparation of several plates containing culture medium with agar and inoculate them with a large inoculum of a clonal culture. After a period of time growth was detectable in half of the replicates and colonies were redistributed over the entire surface of the plate whereas the colony positions remain unchanged in the other half and afterwards all plates are sprayed with the pollutant. The cultures are allowed to grow and the results are visually analyzed: a) pre-selective adaptation: each resistant cell will originate new single colonies all over the spread plates and only a small number of located colonies will arose on the undisturbed plates, or b) post-selective adaptation: both groups of plates will have the same resistant colonies, and variations should be due to chance (Figure 2). This procedure was accomplished by Costas et al. [123] by exposing of microalgae to Tributyl stannane (TBT) and they obtained an 
Citation: Baselga-Cervera B, Lopez-Rodas V, García-Balboa C, Cabilla EIH, Costas E (2016) Mechanisms of Rapid Adaptation to Environmental Stressors in Phytoplankton. J Environ Anal Toxicol 6: 405. doi: 10.4172/2161-0525.1000405

Page 7 of 14

\begin{tabular}{|c|c|c|c|c|c|c|}
\hline Species/strain & Pollutant & $\begin{array}{l}\text { Initial inhibition } \\
\text { Dose }\end{array}$ & $\begin{array}{l}\text { Maximal dose } \\
\text { achieved }\end{array}$ & $\begin{array}{l}\text { Adaptation } \\
\text { increase }\end{array}$ & $\begin{array}{c}\text { Number of } \\
\text { generations }\end{array}$ & Reference \\
\hline Scenedesmus intermedius & Simazine (ppm) & 0.15 & 40.5 & 270 times & $105-120$ & [106] \\
\hline Dictyosphaerium chlorelloides & & 0.15 & 13.5 & 90 times & $90-105$ & \\
\hline M. aeruginosa (3 strains) & & 0.15 & 0.45 & 9 times & $53-90$ & \\
\hline T.suecica & & 0.15 & 1.5 & 10 times & $90-105$ & \\
\hline Phaeodactylum tricornutum & & 0.1 & 0.45 & 4.5 times & $120-135$ & \\
\hline Emiliania huxleyi (3 strains) & & $0.15-0.1$ & 0.15 & $1.5-3$ times & $32-40$ & \\
\hline Isochrysis galbana & & 0.1 & 0.15 & 1.5 times & $40-45$ & \\
\hline Monochrysis lutheri & & 0.1 & 0.15 & 1.5 times & $40-45$ & \\
\hline $\begin{array}{l}\text { Chlamydomonas rehindhardtii } \\
\text { (2strains) }\end{array}$ & Atrazine $(\mu \mathrm{M})$ & 2.3 & 74 & 32 times & $90 \pm 20$ & [119] \\
\hline S. intermedius & Temperature $\left({ }^{\circ} \mathrm{C}\right)$ & 22 & 40 & 1.8 times & $135-150$ & [107] \\
\hline D. chlorelloides & & 22 & 35 & 1.59 times & $90-120$ & \\
\hline M. aeruginosa (3 strains) & & 22 & 35 & 1.59 times & $16-45$ & \\
\hline E. huxleyi (2 strains) & & 22 & - & - & - & \\
\hline I. galbana & & 22 & 35 & 1.59 times & $40-50$ & \\
\hline M. lutheri & & 22 & - & - & - & \\
\hline T. suecica & & 22 & 35 & 1.59 times & $90-120$ & \\
\hline P. tricornutum & & 22 & - & - & - & \\
\hline P. triestinum & & 22 & 30 & 1.36 times & $25-30$ & \\
\hline Nitzschia closterium & & 22 & 30 & 1.36 times & $20-30$ & \\
\hline Navicula sp. & & 22 & 30 & 1.36 times & $30-34$ & \\
\hline Symbiodinium sp. (2 strains) & & 22 & 30 & 1.36 times & $55-70$ & \\
\hline S. intermedius & $\begin{array}{l}\text { Petroleum standard } \\
\text { (V/N) }\end{array}$ & 0.15 & 30 & 200 times & 310 & {$[137,138]$} \\
\hline M. aeruginosa & & 0.15 & 9 & 60 times & 166 & \\
\hline Dunaliella tertiolecta & & 0.15 & 16 & 106,5 times & 120 & \\
\hline S. intermedius & Diesel oil standard (V/V) & 0.15 & 30 & 200 times & 310 & \\
\hline M. aeruginosa & & 0.15 & 9 & 60 times & 166 & \\
\hline D. tertiolecta & & 0.15 & 16 & 106,5 times & 120 & \\
\hline D. chlorelloides & Cooper Sulfate $(\mu \mathrm{M})$ & 12 & 270 & 22 times & $160-183$ & [139] \\
\hline Desmodesmus intermedius & & 12 & 270 & 22 times & $140-160$ & \\
\hline M. aeruginosa & & 2.5 & $10-30$ & $4-12$ times & $20-40$ & \\
\hline
\end{tabular}

Table 2: Maximum adaptation capacity performed in phytoplankton species, indicating the maximal dose achieved, the number of times that the dose was increased during the experiment and the number of generation needed to achieve the last dose assessed.

\begin{tabular}{|c|c|c|c|c|c|}
\hline \multirow{2}{*}{$\begin{array}{c}\text { Adaptation process } \\
\text { Pre-Selective }\end{array}$} & \multicolumn{2}{|c|}{ Type of Selective agent } & \multirow[t]{2}{*}{ Species } & \multirow[t]{2}{*}{$N^{\circ}$ of cases } & \multirow[t]{2}{*}{ Reference } \\
\hline & & & & & \\
\hline & Heavy metals & $\begin{array}{c}\mathrm{OsO}_{4} \\
\left(5 \mathrm{mg} \mathrm{L}^{-1}\right)\end{array}$ & Dc, Ts & 2 & {$[68]$} \\
\hline & & $\begin{array}{c}\mathrm{CrO}_{3} \\
\left(25 \mathrm{mg} \mathrm{L}^{-1}\right)\end{array}$ & Dc & 1 & [140] \\
\hline & & $\begin{array}{c}\mathrm{CuSO}_{4}+5 \mathrm{H}_{2} \mathrm{O} \\
(10 \mu \mathrm{M})\end{array}$ & Ma & 1 & {$[139,141]$} \\
\hline & Antibiotics & $\begin{array}{l}\text { Chloramphenicol } \\
\qquad\left(5 \mathrm{mg} \mathrm{L}^{-1}\right)\end{array}$ & Sc & 1 & [140] \\
\hline & & $\begin{array}{l}\text { Erythromycin } \\
\left(10 \mu \mathrm{L}^{-1}\right)\end{array}$ & $\mathrm{Pp}$ & 1 & [121] \\
\hline & Temperature & $30^{\circ} \mathrm{C}$ & $\mathrm{Pt}, \mathrm{Nc}$ & 2 & \multirow{2}{*}{ [68] } \\
\hline & & $35^{\circ} \mathrm{C}$ & Ma, Ts, Ig & 3 & \\
\hline & Hydrocarbons & $1-3 \% \mathrm{v} / \mathrm{v}$ & $\mathrm{Ma}$ & 2 & \multirow[t]{3}{*}[145,138]{} \\
\hline & & $9-10 \% \mathrm{v} / \mathrm{v}$ & Sc, Dt & 4 & \\
\hline & & $21-30 \% \mathrm{v} / \mathrm{v}$ & Sc & 3 & \\
\hline & $\begin{array}{l}\text { Herbicides and } \\
\text { pesticides }\end{array}$ & Simazine $\left(3,1 \mu \mathrm{gL}^{-1}\right)$ & Dc, Ts & 3 & \multirow[t]{2}{*}[147]{} \\
\hline & & Diquat $\left(120 \mu \mathrm{gL}^{-1}\right)$ & Ts & 1 & \\
\hline & & Lindane $\quad\left(5-40 \mathrm{mgL}^{-1}\right)$ & Ts & 3 & [110] \\
\hline & & Glyphosate $\left(120 \mathrm{mgL}^{-1}\right)$ & Dc & 2 & [142] \\
\hline & & DCMU $\quad(30-50 \mu \mathrm{M})$ & $\mathrm{Dc}, \mathrm{Pp}, \mathrm{Dt}$ & 3 & [121] \\
\hline & & Tributyl stannane $\left(10 \mathrm{mgL}^{-1}\right)$ & $\mathrm{Ts}, \mathrm{Nr}$ & 2 & [123] \\
\hline
\end{tabular}


Citation: Baselga-Cervera B, Lopez-Rodas V, García-Balboa C, Cabilla EIH, Costas E (2016) Mechanisms of Rapid Adaptation to Environmental Stressors in Phytoplankton. J Environ Anal Toxicol 6: 405. doi: 10.4172/2161-0525.1000405

\begin{tabular}{|c|c|c|c|c|c|}
\hline & $\begin{array}{l}\text { Extremophile } \\
\text { ambiances }\end{array}$ & Geothermal waters & $\mathrm{Dc}, \mathrm{Ma}$ & 12 & {$[136]$} \\
\hline & & Mine waters, acid and metal contents & $\mathrm{Dc}, \mathrm{Ma}, \mathrm{Sc}, \mathrm{Cr}, \mathrm{Si}$ & 6 & {$[34,142-156]$} \\
\hline & & Sulphureous waters & $\mathrm{Dc}, \mathrm{Ma}$ & 3 & [156] \\
\hline & & Acid waters & $\mathrm{Dc}, \mathrm{Ma}$ & 1 & {$[107]$} \\
\hline & $\begin{array}{l}\text { Nitro-aromatic- } \\
\text { explosive }\end{array}$ & TNT & Dc, Sc & 2 & {$[157,158]$} \\
\hline \multicolumn{6}{|l|}{ Post-Selective } \\
\hline & Hydrocarbons & $1-3 \% \mathrm{v} / \mathrm{v}$ & Sc, Dt & 6 & \multirow{2}{*}[145,149]{} \\
\hline & & $9-10 \% v / v$ & Sc & 1 & \\
\hline & $\begin{array}{l}\text { Extremophile } \\
\text { ambiances }\end{array}$ & Geothermal waters & $\mathrm{Dc}, \mathrm{Ma}$ & 3 & [136] \\
\hline & & Sulphureous waters & Dc & 1 & [158] \\
\hline & & Acid waters & Dc & 1 & [107] \\
\hline \multicolumn{6}{|l|}{ Non adaptation } \\
\hline & Heavy metals & Osmium $\left(\mathrm{OsO}_{4}\right)\left(5 \mathrm{mgL}^{-1}\right)$ & Ma, Eh & 2 & {$[68]$} \\
\hline & Temperature & $35^{\circ} \mathrm{C}$ & $\mathrm{Pt}, \mathrm{Nc}$ & 2 & [146] \\
\hline & & $40^{\circ} \mathrm{C}$ & Ma, Ts, Ig & 3 & \\
\hline & Hydrocarbons & $9-10 \% \mathrm{v} / \mathrm{v}$ & Ma & 2 & \multirow{2}{*}[145,138]{} \\
\hline & & $21-30 \% \mathrm{v} / \mathrm{v}$ & Ma, Dt & 4 & \\
\hline & $\begin{array}{l}\text { Herbicides and } \\
\text { pesticides }\end{array}$ & Lindane $\left(120 \mathrm{mgL}^{-1}\right)$ & Sc & 1 & {$[110]$} \\
\hline & & Tributyl stannane $\left(10 \mathrm{mgL}^{-1}\right)$ & $\mathrm{P}$ & 1 & [123] \\
\hline & $\begin{array}{l}\text { Extremophile } \\
\text { ambiances }\end{array}$ & Geothermal waters from & Ma, Dc & 9 & {$[136]$} \\
\hline & & Mine waters, acid and metal contents & $\mathrm{Dc}, \mathrm{Ma}, \mathrm{Cr}$ & 3 & {$[151,156]$} \\
\hline & & Sulphureous waters & $\mathrm{Dc}, \mathrm{Ma}$ & 2 & [149] \\
\hline & & Acid waters & $\mathrm{Dc}, \mathrm{Ma}$ & 6 & [107] \\
\hline
\end{tabular}

Table 3: Compilation of the Fluctuation analysis results. Classifying the results as Pre-selective adaptation (rare spontaneous mutations prior to toxic exposition), Postselective (modification of gene expression, epigenetic, etc. induced by the toxic exposition) and no adaptation.

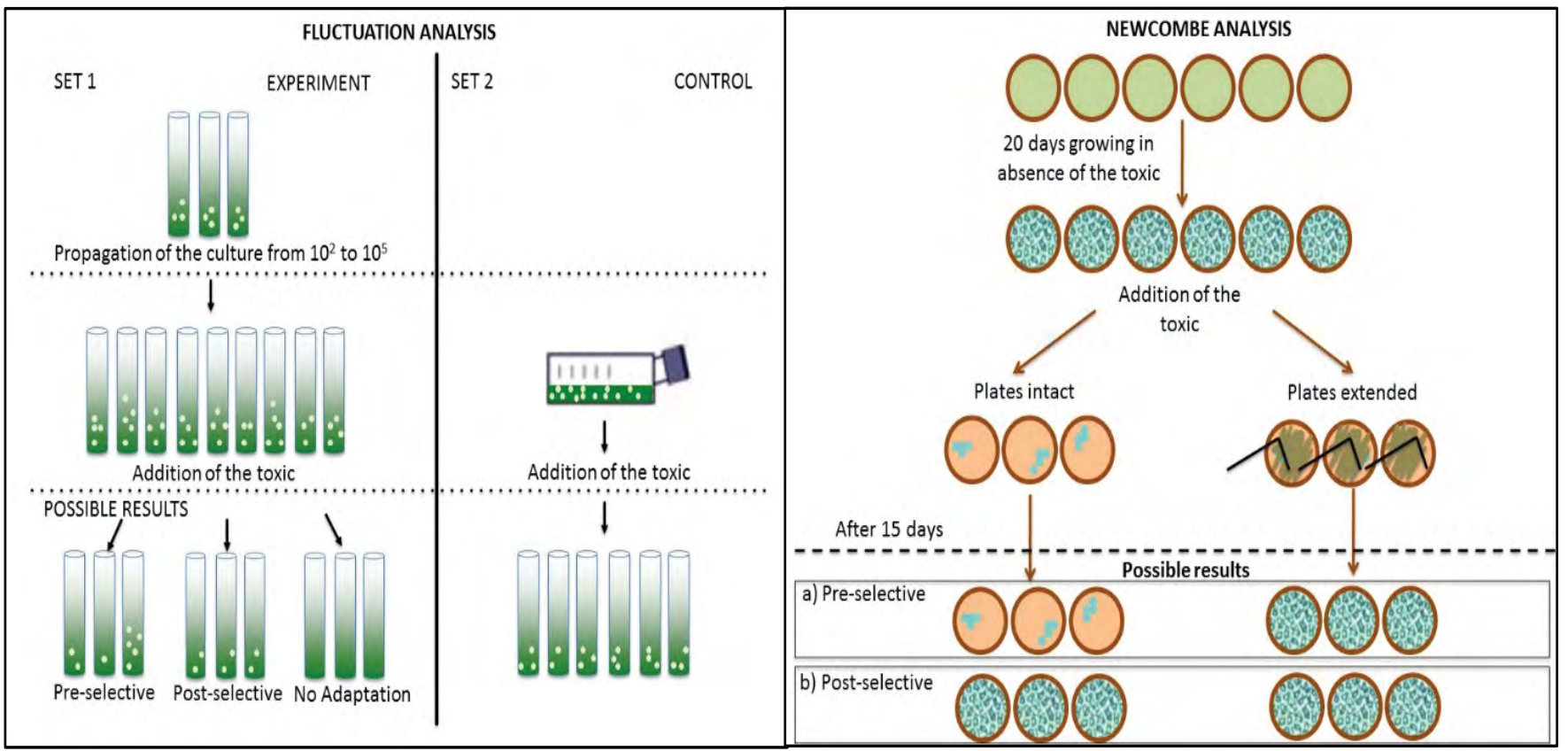

Figure 2: Schematic representation of the modified Fluctuation analysis of Luria et al. [51] and the Newcombe analysis. The fluctuation analysis presents two sets of experiments; set 1 , the exposed trials and set 2 , the control trials. In set 1 , the cultures are inoculated with a low number of cells and let and propagated until a high density is reached. Then the lethal dose of the pollutant is added in all the replicates. Set 2 is inoculated with a large number of cells and directly exposed. In the Newcombe analysis, agar plates are prepared with the culture medium and inoculated with a high number of cells. After 20 days of growth in absence of the toxic, half of the plates are spread and the other half remain un-spread. All the plates are exposed to the toxic agent in the same concentration. After incubation, there is three possible results can be shown in the two experiments: a) pre-selective adaptation, by beneficial pre-existing mutations occurred in the propagation period, b) post-selective adaptation, the adaptation is due to the toxic exposition, or c) no-adaptation. 
Citation: Baselga-Cervera B, Lopez-Rodas V, García-Balboa C, Cabilla EIH, Costas E (2016) Mechanisms of Rapid Adaptation to Environmental Stressors in Phytoplankton. J Environ Anal Toxicol 6: 405. doi: 10.4172/2161-0525.1000405

Page 9 of 14

identical results were obtained with the Fluctuation analysis, T. suecica and Navicula Ramossisima performed a pre-selective adaptation but Prochloron sp. was unable to adapt.

Experimental models like Fluctuation test or Newcome analysis have been the key to demonstrate the origin of adaptive mutations and their presence in natural populations. By means of these tests, it can be demonstrate that in microorganism mutations can rise in the absence of the stressor, and enable to calculate the mutation rate and the population's mutations-selection equilibrium. These experiments also can predict whether or not the organism adapt under harsh environments. For example, from all the analysis performed one out of three were unable to adapt to the extreme ambiance. Like most of the phytoplankton evolutionary experiments, in order to understand individual mechanisms of evolution ambiances are simplify. However, around a $45 \%$ of the experiments were performed with human polluted or natural extreme waters sampled in field, but even with this kind of waters, the conditions remain remote from reality.

\section{Evolutionary adaptation studies as a whole}

Taking into account that one if the hallmarks of the evolutionary experiments is reductionisms, assessing the ERA of pollutants to microbes by means of laboratory tests seams dodgy. Most laboratory evolutionary studies in phytoplankton are oversimplified approaches to predict response to a stressor; both biotic and abiotic traits are restricted. Rather, in natural scenarios multidimensional environmental change exert selection upon many features and the correlations among them may constrain or not adaption.

Non-genetic adaptation trials normally study the adaptation pathways and evolutionary responses in the majority of the cases is mostly indirectly by means of equations and by means of theoretical models. Alternatively, genetic evolutionary studies use clonal or multi-clonal populations to empirically measure the evolutionary and plastic contribution to adaptation. Each type of genetic evolutionary experiment provides knowledge about one or several evolutionary processes, but there are reservations about either type of study when estimating the ERA. Only a few phytoplankton evolutionary studies join either or both multifactorial selective pressures (more than one stressors combinations, like in Rouco et al. [124] and Flores-Moya et al. [110] and populations, several species populations but see [66]. The more complete and detailed is an evolutionary experiment, further comprehension can be obtain of the capacity to evolve and better extrapolation to real possible scenarios can be done.

Phytoplankton would undoubtedly withstand multifaceted environmental change though evolution. The hitherto evidences indicate that phytoplankton presents the potential to outlive by means of plastic responses, standing genetic variability and beneficial novo mutations. A conceptual model linking concentration of pollutants and adaptation strategy is shown in Figure 3, relating toxicity and rapid evolution. Under low concentrations of a pollutant, microalgae can rapidly adapt by plasticity (due to changes in genes expression rather than changes in its nucleotide sequence), but beyond a certain level of toxicity, shorting the recue genotypes of the standing genetic variability could avoid extirpation. Once the genetic variability is override, only a genetic change is the rising of beneficial mutations present in the population. Yet, despite the existence of beneficial mutations, high levels of toxicity could exceed its tolerance and require several gene mutations to confront this obstacle, and to tale this example one-step further, it is plausible that no adaptation takes place. Refer also to the importance of the population size, which drives the role of deterministic process like genetic variants or frequencies of beneficial mutations.

An interesting implementation that can be done in the phytoplankton ecotoxicology evolutionary studies is to systematize DNA sequencing. Genomes study is interesting to understand the effect of pollutants at a molecular level and analyze possible repeated strategies or mutation target and can be combine with ecotoxicology (ecotoxicogenomics), yet few studies in phytoplankton have been made in this ambit. Additionally, complete genomes of the principal key phytoplankton species are necessary.

\section{Limitations and main assets of phytoplankton toxicity- adaptation studies}

One of the principal limitations of the phytoplankton toxicityadaptation studies is to be able to combine more real adaptation scenarios with a better understanding of the principal evolutionary adaptation parameters. The bulk of studies asses the transgenerational adaptation under scenarios modeling more natural populations/ communities or the evolutionary potential of the populations, but few studies combine both. The principal underpinnings of the first kind of studies are a more realistic view of the risk assessment of pollutants and ecological scenarios naturally obtained. Normally, these experiments are made with natural communities or non-clonal species under artificial or natural selective environmental conditions, but while these approaches are better to evaluate the threat of pollutants to natural communities, the evolutionary potential of the populations may left unassessed.

On the contrary, studies of experimental evolutionary responses against pollution can quantify the traits of interest such as fitness, analysis the acting adaptation factor and the adaptive capabilities. Each evolutionary toxicity study in phytoplankton enable certain knowledge about the evolutionary adaptation to a high selective pressure to be revealed. Table 4 shows, in detail, the principal contributions of each type of experiment to disentangle the mechanisms of adaptation. For example, the Fluctuation analysis clarify almost of the adaptation genetics parameters, however the implicated evolutionary forces are poorly disentangle and the maximum adaptation capacity is not analyzed. By contrast, ancestral vs derived population experiments address mainly the evolutionary forces implicated. Each experiment made a different contribution to the knowledge concerning adaptation of a specie to the pollutants but given the infinity of possible speciespollutant association and the complexity of this process, several experiments have to be made to gain a better insight.

In order to make more realistic scenarios of contamination, both types of procedures have analysis the adaptation response to complex environments such as several pollutants exposition, or two or more selective pressures like acidification and temperature. Further investigations on the topic should focus on a combination of possibilities or new designs, yet, untried experiments that account for the maximum number of these adaptation parameters. For example, implement the fluctuation system by including an unexposed control evolving in parallel with the main experiment, so we can study the plastic response and the contribution of the evolutionary response in addition to the genetic adaptation. Furthermore, the standing genetic diversity can be study by performing the same experiment to several clones or start with a no-clonal population and study the differences.

\section{Phytoplankton ecology and evolution: evolutionary rescue phenomenon and advantageous mutations}

Since the invocation 'natura non facit saltus' have been rebutted in 
Citation: Baselga-Cervera B, Lopez-Rodas V, García-Balboa C, Cabilla EIH, Costas E (2016) Mechanisms of Rapid Adaptation to Environmental Stressors in Phytoplankton. J Environ Anal Toxicol 6: 405. doi: 10.4172/2161-0525.1000405

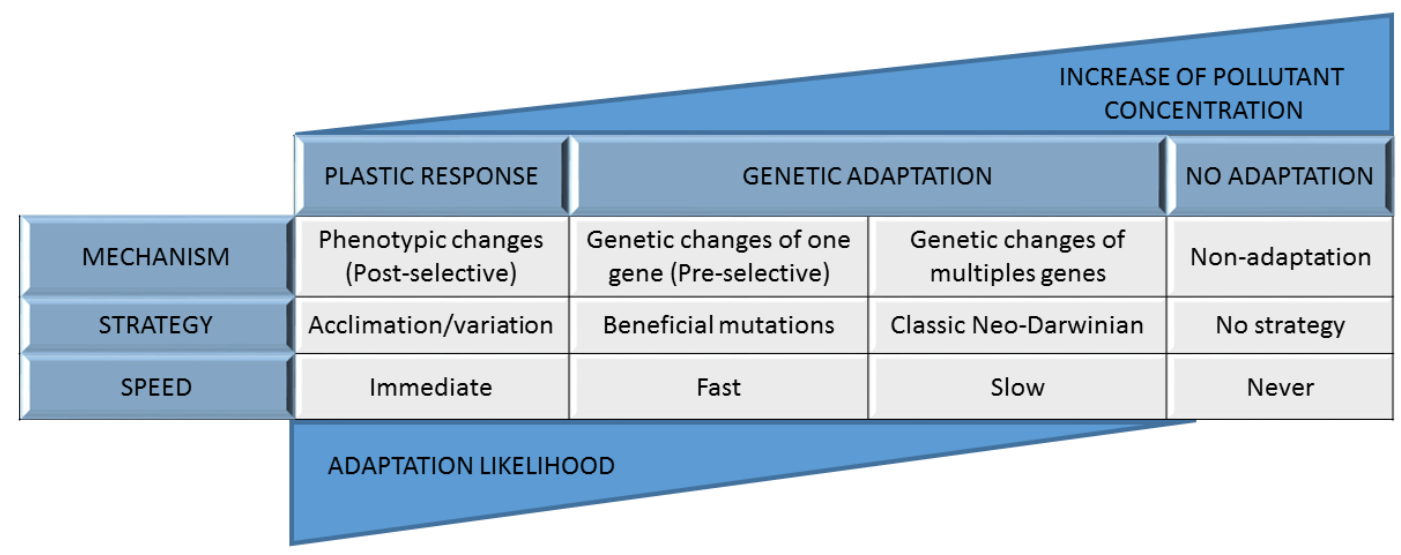

Figure 3: Scheme of the conceptual model linking concentration of pollutant and adaptation strategy of phytoplankton under selective agents. The first immediate response is the plastic response, in which phenotypic changes and standard variations play a crucial role. Once exceeded, only by means of beneficial mutations and genetic changes the species can persists. Finally, when no response can cope with the selective pressure, the extirpation of the populations takes place.

\begin{tabular}{|c|c|c|c|c|c|c|}
\hline \multicolumn{7}{|c|}{ Estimated adaptation parameters } \\
\hline Type of experiments & Adaption capability & $\begin{array}{l}\text { Implicated } \\
\text { evolutionary } \\
\text { forces }\end{array}$ & $\begin{array}{c}\text { Genetic adaptation } \\
\text { mechanisms }\end{array}$ & Mutation rate $(\mu)$ & $\begin{array}{c}\text { Other population } \\
\text { rates }\end{array}$ & $\begin{array}{c}\text { Maximum } \\
\text { adaptation } \\
\text { capacity }\end{array}$ \\
\hline \multicolumn{7}{|l|}{ Non-genetic adaptive studies } \\
\hline $\begin{array}{l}\text { Field/laboratory trans- } \\
\text { generational } \\
\text { Approaches }\end{array}$ & +++ & $+/-$ & - & - & $+/-$ & - \\
\hline \multicolumn{7}{|l|}{ Evolutionary adaptive studies } \\
\hline $\begin{array}{l}\text { Experiments of evolutionary } \\
\text { response }\end{array}$ & ++ & +++ & $+/-$ & - & $+/-$ & - \\
\hline Maximal adaptation capability & +++ & - & - & - & $+/-$ & +++ \\
\hline \multicolumn{7}{|l|}{$\begin{array}{l}\text { Disentangling genetic } \\
\text { adaptation }\end{array}$} \\
\hline Fluctuation analysis & ++ & + & ++ & +++ & +++ & - \\
\hline Newcombe analysis & ++ & + & +++ & $+/-$ & - & - \\
\hline
\end{tabular}

Table 4: The principal contributions of each type of experiment are outlined to disentangle the mechanisms of adaptation.

some cases in microorganisms, the genetic ability to evolve over short periods of time has become the key to eco-evolutionary outcomes.

Nowadays, populations are threaten by the rate of environmental change induced by human contamination and under extreme situations some populations fait to adapt. In this context, a new approach focused on rapid evolution due to genetic variants of large effects is receiving increased interest: in populations subject to severe stress, evolutionary change might occur sufficiently fast to allow population recovery before extinction ensues [121]. This alleged phenomenon is known as evolutionary rescue (ER). Evolutionary rescue occurs when a population that is declining due to by an environmental change adapts to the change sufficiently rapidly to restore positive growth and prevents extinction [125]. One of the hallmarks of ER is that the adaptation depends on the rare rescue genotypes that endure the changes, where the initial size population, fitness distributions and genetic factors are in most cases determinant to avoid extirpation [125-127].

The initial population is consider one of the limits of adaptation, the demographic cost of selection can reduce population significantly before the rescue variants can emerge. A large size population present a higher likelihood of present or obtain the adaptive genotypes $[128,129]$.
The role of fitness in adaptation is well understood in population genetics theory. However, the importance of fitness and the cost of natural selection limiting the capability of a population to sustain the load of mortality required for selection are classic evolutionary problems $[130,131]$, which are now being addressed under the rescue evolutionary approach $[128,132]$. Experimental studies on short time scales, genetic variants of large effects and fitness changes can report problems of practical concern such as the biodiversity crisis and adaptation to pollution, climatic change and over all global change. One examples of this ER approach have been experimentally assess in phytoplankton expose to elevated $\mathrm{CO}_{2}$, algae shown no specific adaptation to $\mathrm{CO}_{2}$ yet the mechanism to concentrate carbon was considerably affected [133].

The standing genetic variability and de novo mutations constrain the ER. The initial variability would influence the rate and severity of the demographic decrease, under extreme stress the rise the fit genotypes can achieve positive growth and ensure adaptation [128]. Few fit organisms that has incurred a great phenotypic change, which, in some circumstances, have the potential to establish a new evolutionary lineage. This kind of organism, result of advantageous 
Citation: Baselga-Cervera B, Lopez-Rodas V, García-Balboa C, Cabilla EIH, Costas E (2016) Mechanisms of Rapid Adaptation to Environmental Stressors in Phytoplankton. J Environ Anal Toxicol 6: 405. doi: 10.4172/2161-0525.1000405

Page 11 of 14

mutants, although uncommon can contribute substantially to the change the population and to the ER. The population substitution can be due a strong selection towards this advantageous mutants, beneficial mutants due to its ability to withstand the selective pressure and rescue the population, and are therefore less likely to be lost by random genetic drift [134]. In particular, the models of Orr and Unckless [135], which are focused on adaptation to a sudden environmental change involving lucky new rare spontaneous mutations in a single locus, are an interesting way to interpret numerous experimental works demonstrating the role of single mutations of large effect on the rapid adaptation to anthropogenic pollutants. This model implies an "oversampling" of those lucky alleles, known as beneficial mutations, which ultimately sweep to high frequency. Certainly, the beneficial mutations are essential to understand the rapid adaptation of phytoplanktonic organisms, to anthropogenic contaminants. Several experimental procedures such as the ratchet protocol or fluctuation analysis demonstrate that rapid adaptation to extreme conditions is due the emergence of mutants present in a population before the exposition, even though this is not a laboratory phenomenon. Astonishingly, in extremely hostile environments where the degree of tolerance of phytoplankton has been largely overcome, after a short time frame (a negligible period of time in terms of evolution) the habitat has been repopulated (e.g., presence of several species of microalgae in Uranium mine waste ponds [94]. Rapid evolution of phytoplankton depends on mutants' genotypes pre-existing in the population (adaptive genotypes by means of beneficial mutations) that are selected because of the environmental conditions and become the new genotypes rising from situations of large-scale changes. Hence, beneficial mutations might ensure survival through a random event.

Undoubtedly, these new approaches will influence the theory and experimental development of evolutionary toxicology.

\section{Conclusion}

Toxicity studies in phytoplankton from acute to multigenerational, are important to understand the scenery of global change, particularly from a pollution threat point-of-view. The ERA of the aquatic ecosystems require of the integration of experimental results, search of molecular and functional relationships. Ecology and evolution experimental procedures may be useful tools to achieve a suitable ERA and to make substantial contributions to the ecotoxicology field. Phytoplankton ecology experiments can aid to achieve more realistic scenarios, addressing the existing diversity using natural populations, the biological networks working with communities and natural conditions, despite the lack of repeatability. Evolutionary toxicity studies join the evolutionary forces taking place because of selective exposition (both over time and at various concentration levels). In short, normally plasticity and pre-existing genetic variability are the initial forces that act to ensure survival under stress. There are interspecific differences in the plasticity response, although most species usually acclimate to low concentrations of contaminants. In contrast, when contamination levels exceed a certain threshold, which is species dependent, adaptation is only possible by genetic changes that confer resistance, in which beneficial mutations may represent the key to survival. Sometimes beneficial mutations imply a large effect in the phytoplankton distancing from the non-mutants genotypes, these mutants only acquires importance when a hostile environment eliminates the competence. Further contamination levels over a period long enough (and usually helped by recombination) can exceed the mutant's tolerance, leading to the classic neo-darwinian strategy in which changes in several genes are required. Once contamination exceeds the boundaries to elicit change, there phytoplankton will not adapt. Taking into account number of possible conditions and the phytoplankton importance and biological diversity, few trials have been done dealing with ecology and evolutionary dynamic of phytoplankton under anthropogenic stressors. Reviews clustering the state of the art in this field might help to encourage more research in this ambit and rise new procedures.

\section{Compliance with the Ethical Standards}

Conflict of Interest: The authors declare that they have no conflict of interest. This article does not contain any studies with human participants or animals performed by any of the authors. Informed consent was obtained from all individual participants included in the study.

\section{Acknowledgements}

Supported by the Spanish Secretaría de Estado de Investigación, Desarrollo e Innovación (Grant CTM 2012-34757 and Grant CTM 2013-44366-R) and Junta de Andalucía project RNM-04744

\section{References}

1. Smith TB, Bernatchez L (2008) Evolutionary change in human-altered environments. Mol Ecol 17: 1-8.

2. Hendry AP, Kinnison MT (1999) Perspective: The Pace of Modern Life: Measuring Rates of Contemporary Microevolution. Evolution (NY) 53:16371653.

3. Palumbi SR (2001) Humans as the world's greatest evolutionary force. Science 293: $1786-1790$

4. Stockwell CA, Hendry AP, Kinnison MT (2003) Contemporary evolution meets conservation biology. Trends Ecol Evol 18: 94-101.

5. Leakey RE (1996) The Sixth Extinction: Patterns of Life and the Future of Humankind.

6. Myers N, Knoll AH (2001) The biotic crisis and the future of evolution. Proc Natl Acad Sci USA 98: 5389-5392.

7. Kolbert E (2014) The Sixth Extinction: An Unnatural History.

8. Balmford A, Green RE, Jenkins M (2003) Measuring the changing state of nature. Trends Ecol Evol 18: 326-330.

9. Larson SJ, Capel PD, Majewski M (1997) Pesticides in Surface Waters: Distribution, Trends, and Governing Factors.

10. Ensminger MP, Budd R, Kelley KC, Goh KS (2013) Pesticide occurrence and aquatic benchmark exceedances in urban surface waters and sediments in three urban areas of California, USA, 2008-2011. Environ Monit Assess 185: 3697-3710.

11. Myers N, Mittermeier RA, Mittermeier CG, da Fonseca GA, Kent J (2000) Biodiversity hotspots for conservation priorities. Nature 403: 853-858.

12. Ehrlich SD (2001) Aims of the functional analysis project. In: Schumann W, Ehrlich SD, Ogasawara N Funtional Analysis of Bacterial Genes: a Practical manual., Â'Chichesta 1-3.

13. Brierley AS, Kingsford MJ (2009) Impacts of climate change on marine organisms and ecosystems. Curr Biol 19: R602-614.

14. Carrera-Martínez D, Mateos-Sanz A, López-Rodas V, Costas E (2010) Microalgae response to petroleum spill: an experimental model analysing physiological and genetic response of Dunaliella tertiolecta (Chlorophyceae) to oil samples from the tanker Prestige. Aquat Toxicol 97: 151-159.

15. Debenest T, Turcotte P, Gagné F, Gagnon C, Blaise C (2012) Ecotoxicological impacts of effluents generated by oil sands bitumen extraction and oil sands lixiviation on Pseudokirchneriella subcapitata. Aquat Toxicol 112-113: 83-91.

16. Moore JW, Ramamoorthy S (2012) Heavy Metals in Natural Waters: Applied Monitoring and Impact Assessment.

17. Sun $Y$, Huang $H$, Sun $Y$, Wang $C$, Shi $X L$, et al. (2013) Ecological risk of estrogenic endocrine disrupting chemicals in sewage plant effluent and reclaimed water. Environ Pollut 180: 339-344. 
Citation: Baselga-Cervera B, Lopez-Rodas V, García-Balboa C, Cabilla EIH, Costas E (2016) Mechanisms of Rapid Adaptation to Environmental Stressors in Phytoplankton. J Environ Anal Toxicol 6: 405. doi: 10.4172/2161-0525.1000405

18. Avar P, Maasz G, Takács P, Lovas S, et al. (2016) HPLC-MS/MS analysis of steroid hormones in environmental water samples. Drug Test Anal 8: 123-127.

19. Halling-Sørensen B, Lützhøft HC, Andersen HR, Ingerslev F (2000) JAC Environmental risk assessment of antibiotics: comparison of mecillinam, trimethoprim and ciprofloxacin 46: 53-58.

20. Kümmerer K (2009) Antibiotics in the aquatic environment--a review--part I. Chemosphere 75: 417-434.

21. Parmesan C, Yohe G (2003) A globally coherent fingerprint of climate change impacts across natural systems. Nature 421: 37-42.

22. Falkowski PG, Raven JA (2013) Aquatic Photosynthesis. 2nd edn.

23. Behrenfeld MJ, O'Malley RT, Siegel DA, McClain CR, Sarmiento JL, et al. (2006) Climate-driven trends in contemporary ocean productivity. Nature 444: $752-755$

24. Boyce DG, Lewis MR, Worm B (2010) Global phytoplankton decline over the past century. Nature 466: 591-596.

25. Margulis L (1982) Five kingdoms: an illustrated guide to the phyla of life on earth.

26. Falkowski PG, Barber RT, Smetacek V V (1998) Biogeochemical Controls and Feedbacks on Ocean Primary Production Science 281: 200-207.

27. Boyd PW, Doney SC (2002) Modelling regional responses by marine pelagic ecosystems to global climate change. Geophys Res Lett 29.

28. Evans MR, Norris KJ, Benton TG (2012) Predictive ecology: systems approaches. Philos Trans R Soc Lond B Biol Sci 367: 163-169.

29. Traas TP, Van Leeuwen CJ (2007) Ecotoxicological Effects. In: Leeuwen CJ van, Vermeire TG (eds). Risk Assessment of Chemicals. Springer Netherlands, Dordrecht, pp: 281-356.

30. Connon RE, Geist J, Werner I (2012) Effect-based tools for monitoring and predicting the ecotoxicological effects of chemicals in the aquatic environment. Sensors (Basel) 12: 12741-12771

31. Loos R, Gawlik BM, Locoro G, Rimaviciute E, Contini S, et al. (2009) EU-wide survey of polar organic persistent pollutants in European river waters. Environ Pollut 157: 561-568.

32. Fischer BB, Roffler S, Eggen RIL (2012) Multiple stressor effects of predation by rotifers and herbicide pollution on different Chlamydomonas strains and potential impacts on population dynamics. Environ Toxicol Chem 31: 28322840.

33. Altenburger R, Ait-Aissa S, Antczak P, Backhaus T, Barceló D, et al. (2015) Future water quality monitoring--adapting tools to deal with mixtures of pollutants in water resource management. Sci Total Environ 512-513: 540-551.

34. Baos R, GarcÃa-Villada L, Agrelo M, et al. (2002) Short-term adaptation of microalgae in highly stressful environments: an experimental model analysing the resistance of Scenedesmus intermedius (Chlorophyceae) to the heavy metals mixture from the Aznalcóllar mine spill. Eur J Phycol 37: 593-600.

35. Tatters AO, Schnetzer A, Fu F, et al. (2013) Short- versus long-term responses to changing $\mathrm{CO} 2$ in a coastal dinoflagellate bloom: implications for interspecific competitive interactions and community structure. Evolution 67: 1879-1891.

36. EPA (2002) Short-term Methods for Estimating the Chronic Toxicity of Effluents and Receiving Waters to Freshwater Organisms.

37. OECD (2002) Guidelines for the Testing of Chemicals. Draft Revised Guideline 201 Freshwater Alga and Cyanobacteria, Growth Inhibition Test. OECD.

38. USEPA-US EPA (2002) The foundation of global action on persitent organic pollutant: a United States perspective.

39. Organization for Economic Cooperation $\mathrm{O}$ (2011) Guidelines for the testing of Chemicals. Section 2: Effect in Biotic Systems.

40. Ventura SP, Gonçalves AM, Gonçalves F, Coutinho JA (2010) Assessing the toxicity on [C3mim][Tf2N] to aquatic organisms of different trophic levels. Aquat Toxicol 96: 290-297.

41. Fernández-Alba AR, Piedra L, Mezcua M, Hernando MD (2002) Toxicity of single and mixed contaminants in seawater measured with acute toxicity bioassays. ScientificWorldJournal 2: 1115-1120.

42. Gatidou G, Thomaidis NS (2007) Evaluation of single and joint toxic effects of two antifouling biocides, their main metabolites and copper using phytoplankton bioassays. Aquat Toxicol 85: 184-191.
43. Stauber JL, Binet MT, Bao VW, Boge J, Zhang AQ, et al. (2008) Comparison of the Qwiklite algal bioluminescence test with marine algal growth rate inhibition bioassays. Environ Toxicol 23: 617-625.

44. Magnusson M, Heimann K, Quayle P, Negri AP (2010) Additive toxicity of herbicide mixtures and comparative sensitivity of tropical benthic microalgae. Mar Pollut Bull 60: 1978-1987.

45. Hartung T, Luechtefeld T, Maertens A, Kleensang A (2013) Integrated testing strategies for safety assessments. ALTEX 30: 3-18.

46. Van Straalen NM (2003) Ecotoxicology becomes stress ecology. Environ Sci Technol 37: 324A-330A.

47. Forbes V, Calow P, Grimm V, et al. (2011) Adding Value to Ecological Risk Assessment with Population Modeling. Val. Forbes Publ 17: 287-299.

48. Bradbury SP, Feijtel TC, Van Leeuwen CJ (2004) Meeting the scientific needs of ecological risk assessment in a regulatory context. Environ Sci Technol 38 : 463A-470A.

49. Ahlers J, Stock F, Werschkun B (2008) Integrated testing and intelligent assessment-new challenges under REACH. Environ Sci Pollut Res Int 15: 565572.

50. Ankley GT, Bennett RS, Erickson RJ, Hoff DJ, Hornung MW, et al. (2010) Adverse outcome pathways: a conceptual framework to support ecotoxicology research and risk assessment. Environ Toxicol Chem 29: 730-741.

51. Kramer VJ, Etterson MA, Hecker M, Murphy CA, Roesijadi G, et al. (2011) Adverse outcome pathways and ecological risk assessment: bridging to population-level effects. Environ Toxicol Chem 30: 64-76.

52. Burden N, Sewell F, Andersen ME, Boobis A, Chipman JK, et al. (2015) Adverse Outcome Pathways can drive non-animal approaches for safety assessment. J Appl Toxicol 35: 971-975

53. Bednarska AJ, Jevtić DM, Laskowski R (2013) More ecological ERA incorporating natural environmental factors and animal behavior. Integr Environ Assess Manag 9: e39-46.

54. Villeneuve DL, Garcia-Reyero N (2011) Vision \& strategy: Predictive ecotoxicology in the 21st century. Environ Toxicol Chem 30: 1-8.

55. Luria SE, Delbrück M (1943) Mutations of Bacteria from Virus Sensitivity to Virus Resistance. Genetics 28: 491-511.

56. Travisano M, Mongold JA, Bennett AF, Lenski RE (1995) Experimental tests of the roles of adaptation, chance, and history in evolution. Science 267: 87-90.

57. Thompson JN (1998) Rapid evolution as an ecological process. Trends Ecol Evol 13: 329-332.

58. Hairston NG, Ellner SP, Geber MA, et al. (2005) Rapid evolution and the convergence of ecological and evolutionary time. Ecol Lett 8: 1114-1127.

59. Jukes TH, Kimura M (1984) Evolutionary constraints and the neutral theory. J Mol Evol 21: 90-92.

60. Nei M, Suzuki Y, Nozawa M (2010) The neutral theory of molecular evolution in the genomic era. Annu Rev Genomics Hum Genet 11: 265-289.

61. Li W-H (1997) Molecular Evolution.

62. Hartl DL, Clark AG (2007) Principles of Population Genetics.

63. Hallegraeff GM (2010) Ocean Climate Change, Phytoplankton Community Responses, And Harmful Algal Blooms: A Formidable Predictive Challenge. J Phycol 46: 220-235.

64. Echeveste P, Dachs J, Berrojalbiz N, Agustí S (2010) Decrease in the abundance and viability of oceanic phytoplankton due to trace levels of complex mixtures of organic pollutants. Chemosphere 81: 161-168.

65. Leboulanger C, Rimet F, de Lacotte M, Bérard A (2001) Effects of atrazine and nicosulfuron on freshwater microalgae. Environ Int 26: 131-135.

66. Low-Décarie ET, Fussmann GF, Bell G (2011) The effect of elevated CO2 on growth and competition in experimental phytoplankton communities. Glob Chang Biol 17: 2525-2535.

67. Wu Y (2013) Mercury toxicity and detoxification in marine phytoplankton.

68. Marvá F, García-Balboa C, Baselga-Cervera B, Costas E (2014) Rapid adaptation of some phytoplankton species to osmium as a result of spontaneous mutations. Ecotoxicology 23: 213-220. 
Citation: Baselga-Cervera B, Lopez-Rodas V, García-Balboa C, Cabilla EIH, Costas E (2016) Mechanisms of Rapid Adaptation to Environmental Stressors in Phytoplankton. J Environ Anal Toxicol 6: 405. doi: 10.4172/2161-0525.1000405

69. Jirtle RL, Skinner MK (2007) Environmental epigenomics and disease susceptibility. Nat Rev Genet 8: 253-262.

70. Skinner MK, Manikkam M, Guerrero-Bosagna C (2010) Epigenetic transgenerational actions of environmental factors in disease etiology. Trends Endocrinol Metab 21: 214-222.

71. Feng S, Cokus SJ, Zhang X, Chen PY, Bostick M, et al. (2010) Conservation and divergence of methylation patterning in plants and animals. Proc Natl Acad Sci U S A 107: 8689-8694

72. Zemach A, McDaniel IE, Silva P, Zilberman D (2010) Genome-wide evolutionary analysis of eukaryotic DNA methylation. Science 328: 916-919.

73. Pomati F, Nizzetto L (2013) Assessing triclosan-induced ecological and transgenerational effects in natural phytoplankton communities: a trait-based field method. Ecotoxicology 22: 779-794.

74. Bickham JW, Smolen MJ (1994) Somatic and heritable effects of environmental genotoxins and the emergence of evolutionary toxicology. Environ Health Perspect 102 Suppl 12: 25-28.

75. Bickham JW, Sandhu S, Hebert PD, Chikhi L, Athwal R (2000) Effects of chemical contaminants on genetic diversity in natural populations: implications for biomonitoring and ecotoxicology. Mutat Res 463: 33-51.

76. Matson CW, Lambert MM, McDonald TJ, Autenrieth RL, Donnelly KC, et al. (2006) Evolutionary toxicology: population-level effects of chronic contaminant exposure on the marsh frogs (Rana ridibunda) of Azerbaijan. Environ Health Perspect 114: 547-552.

77. Bickham JW (2011) The four cornerstones of Evolutionary Toxicology. Ecotoxicology 20: 497-502.

78. Harmon LJ, Matthews B, Des Roches S, Chase JM, Shurin JB, et al. (2009) Evolutionary diversification in stickleback affects ecosystem functioning. Nature 458: $1167-1170$

79. Ellner SP, Geber MA, Hairston NG Jr (2011) Does rapid evolution matter? Measuring the rate of contemporary evolution and its impacts on ecological dynamics. Ecol Lett 14: 603-614.

80. Zhang J (2012) Genetic redundancies and their evolutionary maintenance. Adv Exp Med Biol 751: 279-300

81. Muschick M, Indermaur A, Salzburger W (2012) Convergent evolution within an adaptive radiation of cichlid fishes. Curr Biol 22: 2362-2368.

82. Scheffer M, Vergnon R, van Nes EH, Cuppen JG, Peeters ET, et al. (2015) The Evolution of Functionally Redundant Species; Evidence from Beetles. PLoS One 10: e0137974

83. Chevin LM, Gallet R, Gomulkiewicz R, Holt RD, Fellous S (2013) Phenotypic plasticity in evolutionary rescue experiments. Philos Trans R Soc Lond B Biol Sci 368: 20120089

84. Schaum CE (2014) Plasticity predicts evolution in a marine alga. Proc Biol Sci 281.

85. Valladares F, Matesanz S, Guilhaumon F, Araújo MB, Balaguer L, et al. (2014) The effects of phenotypic plasticity and local adaptation on forecasts of species range shifts under climate change. Ecol Lett 17: 1351-1364.

86. Côte J, Bouétard A, Pronost Y, Besnard AL, Coke M, et al. (2015) Genetic variation of Lymnaea stagnalis tolerance to copper: A test of selection hypotheses and its relevance for ecological risk assessment. Environ Pollut 205: 209-217.

87. Thébault E, Loreau M (2005) Trophic interactions and the relationship between species diversity and ecosystem stability. Am Nat 166: E95-114.

88. Tilman D, Reich PB, Knops JM (2006) Biodiversity and ecosystem stability in a decade-long grassland experiment. Nature 441: 629-632.

89. Ptacnik R, Solimini AG, Andersen T, Tamminen T, Brettum P, et al. (2008) Diversity predicts stability and resource use efficiency in natural phytoplankton communities. Proc Natl Acad Sci U S A 105: 5134-5138.

90. Chalar G (2009) The use of phytoplankton patterns of diversity for algal bloom management. Limnol - Ecol Manag InI Waters 39: 200-208.

91. Lohbeck KT, Riebesell U, Reusch TBH (2012) Adaptive evolution of a key phytoplankton species to ocean acidification. Nat Geosci 5: 346-351.

92. Flöder S, Sommer U (1999) Diversity in planktonic communities: an experimental test of the intermediate disturbance hypothesis. Limnol Oceanogr 44: $1114-1119$
93. Schmitt-Jansen M, Veit U, Dudel G, Altenburger R (2008) An ecological perspective in aquatic ecotoxicology: approaches and challenges. Basic Appl Ecol 9: 337-345

94. García-Balboa C, Baselga-Cervera B, García-Sanchez A, Igual JM, LopezRodas V, et al. (2013) Rapid adaptation of microalgae to bodies of water with extreme pollution from uranium mining: an explanation of how mesophilic organisms can rapidly colonise extremely toxic environments. Aquatic Toxico 144: 116-123

95. Müller M, Schulz K, Riebesell U (2010) Effects of long-term high $\mathrm{CO}_{2}$ exposure on two species of coccolithophores. Biogeosciences 7: 1109-1116.

96. Stachowski-Haberkorn S, Jérôme M, Rouxel J, Khelifi C, Rincé M, et al. (2013) Multigenerational exposure of the microalga Tetraselmis suecica to diuron leads to spontaneous long-term strain adaptation. Aquat Toxicol 140: 380-388.

97. Chevin LM, Lande R, Mace GM (2010) Adaptation, plasticity, and extinction in a changing environment: towards a predictive theory. PLoS Biol 8: e1000357.

98. Merilä J, Hendry AP (2014) Climate change, adaptation, and phenotypic plasticity: the problem and the evidence. Evol Appl 7: 1-14.

99. Lenski RE, Sniegowski PD (1995) "Adaptive mutation": the debate goes on Science 269: 285-288

100. Sniegowski PD (2005) Linking mutation to adaptation: overcoming stress at the spa. New Phytol 166: 360-362.

101. Crawfurd KJ, Raven JA, Wheeler GL, Baxter EJ, Joint I (2011) The response of Thalassiosira pseudonana to long-term exposure to increased $\mathrm{CO}_{2}$ and decreased pH. PLoS One 6: e26695.

102. Jin P, Gao K, Beardall J (2013) Evolutionary responses of a coccolithophorid Gephyrocapsa oceanica to ocean acidification. Evolution 67: 1869-1878.

103. Reusch TB (2014) Climate change in the oceans: evolutionary versus phenotypically plastic responses of marine animals and plants. Evol Appl 7: 104-122.

104. Collins S, Rost B, Rynearson TA (2014) Evolutionary potential of marine phytoplankton under ocean acidification. Evol Appl 7: 140-155.

105. Rynearson TA, Lin EO, Armbrust EV (2009) Metapopulation Structure in the Planktonic Diatom Ditylum brightwellii (Bacillariophyceae). Protist 160: 111-121.

106. Huertas IE, Rouco M, López-Rodas V, Costas E (2010) Estimating the capability of different phytoplankton groups to adapt to contamination: herbicides will affect phytoplankton species differently. New Phytol 188: 478487.

107. Huertas IE, Rouco M, López-Rodas V, Costas E (2011) Warming will affect phytoplankton differently: evidence through a mechanistic approach. Proc Biol Sci 278: 3534-3543.

108. Lanfear R, Kokko H, Eyre-Walker A (2014) Population size and the rate of evolution. Trends Ecol Evol 29: 33-41.

109. Morgan AJ, Kille P, Stürzenbaum SR (2007) Microevolution and ecotoxicology of metals in invertebrates. Environ Sci Technol 41: 1085-1096.

110. Flores-Moya A, Rouco M, García-Sánchez MJ, García-Balboa C, González $R$, et al. (2012) Effects of adaptation, chance, and history on the evolution of the toxic dinoflagellate Alexandrium minutum under selection of increased temperature and acidification. Ecol Evol 2: 1251-1259.

111. Reusch TB, Boyd PW (2013) Experimental evolution meets marine phytoplankton. Evolution 67: 1849-1859.

112. Litchman E, Edwards K, Klausmeier C, Thomas M (2012) Phytoplankton niches, traits and eco-evolutionary responses to global environmental change. Mar Ecol Prog Ser 470: 235-248.

113. Gould SJ (1989) Wonderful Life: The Burges Shale and the Nature of History

114. Gould SJ, Lewontin RC (1979) The spandrels of San Marco and the Panglossian paradigm: a critique of the adaptationist programme. Proc $\mathrm{R}$ Soc Lond B Biol Sci 205: 581-598.

115. Boyd PW, Strzepek R, Fu F, Hutchins DA (2010) Environmental control of open-ocean phytoplankton groups: Now and in the future. Limnol Oceanogr 55: 1353-1376.

116. Liebe B, Fock HP (1992) Growth and adaptation of the green alga Chlamydomonas reinhardtii on diesel exhaust particle extracts. J Gen Microbiol 138: 973-978. 
Citation: Baselga-Cervera B, Lopez-Rodas V, García-Balboa C, Cabilla EIH, Costas E (2016) Mechanisms of Rapid Adaptation to Environmental Stressors in Phytoplankton. J Environ Anal Toxicol 6: 405. doi: 10.4172/2161-0525.1000405

117. Dahl B, Blanck $H$ (1996) Toxic effects of the antifouling agent irgarol 1051 on periphyton communities in coastal water microcosms. Mar Pollut Bull 32: 342-350.

118. Lynch M, Lande $R$ (1993) Evolution and extinction in response to environmental change. In: Kareiva PM (ed). Biotic Interactions and Global Change. pp: 234-250.

119. Reboud X, Majerus N, Gasquez J, Powles S (2007) Chlamydomonas reinhardtii as a model system for pro-active herbicide resistance evolution research. Biol J Linn Soc 91: 257-266.

120. Moraleda GO, Rodas VL, Costas EC, Florez DH, Pampín EM (2010) Biosensors based on microalgae for the detection of environmental pollutants. US20100248286 A1

121. Lopez-Rodas V, Agrelo M, Carrillo E, Ferrero L, Larrauri A, et al. (2001) Resistance of microalgae to modern water contaminants as the result of rare spontaneous mutations. Eur J Phycol 36: 179-190.

122. Newcombe HB (1949) Origin of bacterial variants. Nature 164: 150-151.

123. Costas E, Gonzalez R, López-Rodas V, Huertas IE (2013) Mutation of microalgae from antifouling sensitivity to antifouling resistance allows phytoplankton dispersal through ships' biofouling. Biol Invasion 15: 17391750.

124. López-Rodas V, Rouco M, Sánchez-Fortún S, Flores-Moya A, Costas E (2011) Genetic adaptation and acclimation of phytoplankton along a stress gradient in the extreme waters of the agrio river-caviahue lake (Argentina). J Phycol 47: 1036-1043.

125. Gonzalez A, Ronce O, Ferriere R, Hochberg ME (2013) Evolutionary rescue: an emerging focus at the intersection between ecology and evolution. Philos Trans R Soc Lond B Biol Sci 368: 2012.0404.

126. Carlson SM, Cunningham CJ, Westley PA (2014) Evolutionary rescue in a changing world. Trends Ecol Evol 29: 521-530.

127. Orr HA, Unckless RL (2008) Population extinction and the genetics of adaptation. Am Nat 172: 160-169.

128. Bell G (2013) Evolutionary rescue and the limits of adaptation. Philos Trans R Soc Lond B Biol Sci 368: 20120080

129. Gomulkiewicz R, Holt RD (1995) When does evolution by natural selection prevent extinction? Evolution 49: 201-207.

130. Haldane JBS (1939) The effect of variation of fitness. Am Nat 71: 337-349.

131. Smith JM (1989) The causes of extinction. Philos Trans R Soc Lond B Biol Sci 325: 241-252.

132. Bell G, Gonzalez A (2011) Adaptation and evolutionary rescue in metapopulations experiencing environmental deterioration. Science 332 $1327-1330$.

133. Bell G, Collins S (2008) Adaptation, extinction and global change. Evol Appl 1: 3-16.

134. Eyre-Walker A, Keightley PD (2007) The distribution of fitness effects of new mutations. Nat Rev Genet 8: 610-618.

135. Orr HA, Unckless RL (2014) The population genetics of evolutionary rescue PLoS Genet 10: e1004551.

136. Costas E, Flores-Moya A, López-Rodas V (2008) Rapid adaptation of phytoplankters to geothermal waters is achieved by single mutations: were extreme environments 'Noah's Arks' for photosynthesizers during the Neoproterozoic ‘snowball Earth'? New Phytologist 180: 922-932.

137. Rouco M, LÃ 3 pez-Rodas V, Flores-Moya A, Costas E (2011) Evolutionary changes in growth rate and toxin production in the cyanobacterium Microcystis aeruginosa under a scenario of eutrophication and temperature increase. Microb Ecol 62: 265-273.

138. Romero-Lopez J, Lopez-Rodas V, Costas E (2012) Estimating the capability of microalgae to physiological acclimatization and genetic adaptation to petroleum and diesel oil contamination. Aquat Toxicol 124: 227-237.

139. Rouco M, López-Rodas V, González R, Huertas IE, García-Sánchez MJ, et al. (2014) The limit of the genetic adaptation to copper in freshwater phytoplankton. Oecologia 175: 1179-1188.

140. Sánchez-Fortün S, López-Rodas V, Navarro M, Marvá F, D'ors A, et al. (2009a) Toxicity and adaptation of Dictyosphaerium chlorelloides to extreme chromium contamination. Environ Toxicol Chem 28: 1901-1905.
141. López-Rodas V, Flores-Moya A, Maneiro E, Perdigones N, Marva F, et al. (2006b) Resistance to glyphosate in the cyanobacterium Microcystis aeruginosa as result of pre-selective mutations. Evol Ecol 21: 535-547.

142. García-Villada L, Rico M, Altamirano MM, Sánchez-Martín L, López-Rodas V, et al. (2004) Occurrence of copper resistant mutants in the toxic cyanobacteria Microcystis aeruginosa: characterisation and future implications in the use of copper sulphate as algaecide. Water Res 38: 2207-2213.

143. López-Rodas V, Flores-Moya A, Maneiro E, Perdigones N, Marva F, et al. (2007) Resistance to glyphosate in the cyanobacterium Microcystis aeruginosa as result of pre-selective mutations. Evol Ecol 21: 535-547.

144. Sánchez-Fortún S, Marvá F, Rouco M, Costas E, López-Rodas V, et al. (2009) Toxic effect and adaptation in Scenedesmus intermedius to anthropogenic chloramphenicol contamination: genetic versus physiological mechanisms to rapid acquisition of xenobiotic resistance. Ecotoxicology 18: 481-487.

145. Carrera-Martinez D, Mateos-Sanz A, Lopez-Rodas V, Costas E (2011) Adaptation of microalgae to a gradient of continuous petroleum contamination. Aquat Toxicol 101: 342-350.

146. Marvá F, García-Balboa C, Baselga-Cervera B, Costas E (2014) Rapid adaptation of some phytoplankton species to osmium as a result of spontaneous mutations. Ecotoxicology 23: 213-220.

147. Marvá F, López-Rodas V, Rouco M, Navarro M, Toro FJ, et al. (2010) Adaptation of green microalgae to the herbicides simazine and diquat as result of pre-selective mutations. Aquat Toxicol 96: 130-134.

148. Costas E, Maneiro E, Rodas VL (2006) Adaptation of cyanobacteria and microalgae to extreme environmental changes derived from anthropogenic pollution. Limnetica 25: 403-410.

149. Flores-Moya A, Costas E, López-Rodas V (2008) Roles of adaptation, chance and history in the evolution of the dinoflagellate Prorocentrum triestinum. Naturwissenschaften 95: 697-703.

150. Rico M, Altamirano M, López-Rodas V, Costas E (2006) Analysis of polygenic traits of Microcystis aeruginosa (Cyanobacteria) strains by Restricted Maximum Likelihood (REML) procedures: 2. Microcystin net production, photosynthesis and respiration. Phycologia 45: 243-248.

151. Costas E, Flores-Moya A, Perdigones N, Maneiro E, Blanco JL, et al. (2007) How eukaryotic algae can adapt to the Spain's Rio Tinto: a neo-Darwinian proposal for rapid adaptation to an extremely hostile ecosystem. New Phyto 175: 334-339.

152. López-Rodas V, Marvá F, Rouco M, Costas E, Flores-Moya A (2008) Adaptation of the chlorophycean Dictyosphaerium chlorelloides to stressful acidic, mine metal-rich waters as result of pre-selective mutations. Chemosphere 72: 703-707.

153. López-Rodas V, Marvá F, Costas E, Flores-Moya A (2008) Microalgal adaptation to a stressful environment (acidic, metal-rich mine waters) could be due to selection of pre-selective mutants originating in non-extreme environments. Environ Exp Bot 64: 43-48.

154. Flores-Moya A, Costas E, Bañares-España E, García-Villada L, Altamirano $M$, et al. (2005) Adaptation of Spirogyra insignis (Chlorophyta) to an extreme natural environment (sulphureous waters) through preselective mutations. New Phytol 166: 655-661.

155. López-Rodas V, Costas E, Maneiro E, Marvá F, Rouco M, et al. (2009) Living in Vulcan's forge: Algal adaptation to stressful geothermal ponds on Vulcano Island (southern Italy) as a result of pre-selective mutations. Phycol Res 57: 111-117.

156. del Mar Fernández-Arjona M, Bañares-España E, García-Sánchez MJ, Hernández-López M, López-Rodas V, et al. (2013) Disentangling mechanisms involved in the adaptation of photosynthetic microorganisms to the extreme sulphureous water from Los Baños de Vilo (S Spain). Microb Ecol 66: 742-751.

157. García-Villada L, López-Rodas V, Bañares-España E, Flores-Moya A, Agrelo M, Martín-Otero L, et al. (2002) Evolution of microalgae in highy stressing environments: an experimental model analyzing the rapid adadtation of Dictyosphaerium Chlorelloides (Chlorophyceae) from sensitivity to resistance against 2,4,6-trinitrotolueni by rare preselective mutations. J Phycol 38 : 1074-1081.

158. González R, García-Balboa C, Rouco M, Lopez-Rodas V, Costas E (2012) Adaptation of microalgae to lindane: a new approach for bioremediation. Aquat Toxicol 109: 25-32. 